\title{
Pemberdayaan Pengungsi dalam Program Persiapan Kerja
}

\author{
Sri Hapsari Wijayanti*1, Aditya Gunawan, ${ }^{2}$ Pinky Sibuea ${ }^{3}$ \\ 1,2,3Fakultas Ekonomi dan Bisnis, Universitas Katolik Indonesia Atma Jaya \\ *e-mail: sri.hapsari@atmajaya.ac.id ${ }^{1}$ aditya.gunawan@atmajaya.ac.id ${ }^{2}$, pinkysibuea@gmail.com ${ }^{3}$
}

\begin{abstract}
Indonesia, through UNHCR, has been dealing with the refugee problem for the past few years. Some companies that are open to refugees provide internship opportunities, but they are not prepared with good CVS and interview skills. Therefore, through this training program, it is expected that these refugees have the provision to be able to prepare themselves better before entering the workplace. The purpose of community service is to provide a CV and cover letter writing skills and conduct interviews. Participants are refugees living in Jakarta, Bogor, Puncak, and Tangerang, numbering 35 people. This activity was held in July 2021 for two days. This method of activity is training as well as the practice of in-person interviews with vendors. The results of the training showed increasing participants' knowledge about writing a CV, cover letter, and conducting interviews. Participants also welcomed the opportunity for an interview with vendors.
\end{abstract}

Keywords: UNHCR, cover letter, CV, refugees, interview, skill

\begin{abstract}
Abstrak
Indonesia, melalui UNHCR, menangani masalah pengungsi sejak beberapa tahun terakhir. Beberapa perusahaan yang terbuka bagi pengungsi memberikan kesempatan magang, namun mereka tidak siap dengan CV dan kemampuan wawancara yang baik. Oleh karena itu, melalui program pelatihan ini diharapkan para pengungsi ini memiliki bekal untuk dapat mempersiapkan diri dengan lebih baik lagi sebelum memasuki dunia kerja. Tujuan pengabdian kepada masyarakat ini adalah memberikan keterampilan menulis CV dan surat lamaran serta melakukan wawancara. Peserta adalah pengungsi yang tinggal di Jakarta, Bogor, Puncak, dan Tangerang, berjumlah 35 orang. Waktu pelaksanaan pada Juli 2021 selama dua hari. Metode kegiatan ini adalah pelatihan sekaligus praktik wawancara langsung dengan pihak perusahaan. Hasil pelatihan menunjukkan ada peningkatan pengetahuan peserta tentang menulis $\mathrm{CV}$, surat lamaran, dan melakukan wawancara. Peserta juga menyambut baik adanya kesempatan wawancara langsung dengan pihak perusahaan.
\end{abstract}

Kata kunci: UNHCR, surat lamaran, CV, pengungsi, wawancara, keahlian

\section{PENDAHULUAN}

Dilaporkan oleh Komisi PBB urusan pengungsi, United Nations High Commission for Refugees (UNHCR), jumlah pengungsi mencapai 13.700 orang (UNHCR, Desember 2020). Para pengungsi berasal dari berbagai negara, antara lain Mesir, Afghanistan, Somalia, Sudan, Ethiopia, Irak, Iran, dan Libya. Mereka menetap sementara di Indonesia dan harus menunggu bertahuntahun untuk mendapat izin tinggal di negara tujuan (Elvianti, 2020). Di Indonesia mereka mendapat penanganan khusus dari pemerintah. Urusan penanganan pengungsi telah disahkan dalam Peraturan Presiden Nomor 125 Tahun 2016 tentang Penanganan Pengungsi dari Luar Negeri. Atas dasar kemanusiaan, perlu ada kolabarosi antara pemerintah, UNHCR/IOM (International Organization for Migration), dan masyarakat lokal dalam menangani keberadaan pengungsi di tempat-tempat pengungsian (Yani \& Zulkarnain, 2019). Dari bantuan IOM dan organisasi donor lain, pengungsi dapat memenuhi kebutuhan hidup sehari-hari. Akan tetapi, kenyataannya keberadaan mereka di suatu masyarakat tidak jarang menimbulkan masalah baru bagi masyarakat tersebut atau bagi diri pengungsi sendiri.

Masalah yang muncul dengan kehadiran pengungsi meliputi masalah identitas, kepastian hukum, kepastian status di negara transit, kesehatan, adaptasi, serta terbatasnya akses pendidikan anak-anak, dan izin bekerja (Jamaan et al., 2020; Nola, 2021). Pengungsi yang tinggal di Indonesia kehilangan hak untuk bekerja dan mendapatkan pendidikan secara formal. Anakanak pengungsi, khususnya yang tinggal di Cisarua Refugees Learning Centre di Cisarua Bogor, 
kurang dapat berinteraksi dengan masyarakat setempat. Selain mereka tidak dapat mengenyam pendidikan, mereka juga kurang dapat berbahasa Indonesia. Karena itulah, Elvianti menginisiasi kegiatan pengenalan budaya Indonesia dan bahasa Indonesia sehari-hari kepada anak-anak pengungsi asal Afghanistan dan Pakistan di sana (Elvianti, 2020). Kegiatan serupa juga telah dilakukan kepada para pengungsi dewasa melalui pelatihan bahasa Indonesia praktis yang menunjukkan hasil belajar yang baik (Wijayanti, 2020).

Dengan kemampuan berbahasa Indonesia atau bahasa asing lainnya, pendidikan tinggi yang disandangnya, serta pengalaman bekerja di negara asal mereka, ternyata belum cukup bagi pengungsi untuk mendapatkan pekerjaan di Indonesia. Sesuai dengan hukum yang berlaku, pengungsi tidak diperkenankan bekerja tetap di sektor formal karena status mereka, terutama karena mereka tinggal di negara yang belum merativikasi Konvensi 1951 tentang pengungsi, seperti Indonesia (Jamaan et al., 2020; Yani \& Zulkarnain, 2019).

Dari survei terkini (Mei 2021) terhadap perwakilan 27 pengungsi yang tinggal di Jakarta, Bogor, Puncak, Cisarua, dan Tangerang diketahui usia kebanyakan pengungsi 25 tahun (52\%) dan belum menikah (74\%). Para pengungsi, yang mayoritas laki-laki ini, sudah berada di Indonesia sekitar 6-10 tahun (52\%). Mereka umumnya menguasai bahasa Inggris (74\%) dan sudah dapat berbahasa Indonesia sehari-hari (56\%). Sebanyak 67\% dari mereka tidak bekerja. Tentu saja mereka tidak dapat terus-menerus mengandalkan bantuan dari sanak saudara di negaranya atau bantuan dari IOM/UNHCR. Maka, mencari pekerjaan menjadi tujuan utama mereka agar dapat bertahan hidup. Dari hasil survei diketahui sebanyak 59\% menyatakan ingin bekerja dan 52\% ingin berwirausaha. Dari survei tersebut dapat diketahui bahwa pengungsi tergolong usia produktif yang memiliki kemauan untuk bekerja atau menciptakan pekerjaan sendiri. Keinginan itu dilandasi atas kebutuhan hidup (Nola, 2021).

Untuk membantu mereka terjun ke dunia kerja, banyak faktor yang perlu dipersiapkan, seperti kemampuan komunikasi baik lisan maupun tulis. Karena berada di Indonesia dan akan bekerja di perusahaan Indonesia, kemampuan berbahasa Indonesia menjadi persyaratan utama. Bahasa Indonesia menjadi alat komunikasi mereka dengan siapa pun di dunia kerja nantinya dan merupakan modal dasar untuk dapat berinteraksi di tengah masyarakat dalam situasi formal (Oktavia \& Putra, 2018).

Khususnya untuk mereka yang ingin bekerja secara formal di perusahaan, meskipun tidak dapat bekerja secara tetap, pengungsi akan berhadapan dengan proses rekruitmen, antara lain wawancara. Sebelum mendapat kesempatan wawancara, mereka harus mengirimkan surat lamaran pekerjaan dan CV. Karena itu, mempersiapkan mereka dengan keterampilan menulis CV dan teknik wawancara yang lazim dilakukan dalam budaya Indonesia perlu mereka pahami. Inilah yang menjadi tujuan program SILVER (self improvement lesson, vocational education for refugees) 2020, lanjutan program SILVER 2019.

\section{METODE}

Pengabdian kepada masyarakat ini dilaksanakan secara daring melalui aplikasi Zoom. Waktu pelaksanaan 24 Juli dan 29 Juli 2021, masing-masing selama tiga jam. Untuk mengetahui kemampuan awal peserta, peserta diberikan prates terkait CV dan wawancara sehari sebelum pelaksanaan. Peserta yang mendaftar kegiatan ini berjumlah 73 orang, tetapi dari seleksi terhadap kemampuan menceritakan kemampuan diri sendiri dalam bahasa Indonesia, hanya 50 orang yang terpilih. Dari 50 orang tersebut, yang konfirmasi mengikuti pelatihan berjumlah 35 orang dengan komposisi jumlah laki-laki $83 \%$ dan perempuan 17\%, mayoritas berasal dari Afghanistan (46\%).

Kegiatan ini dilakukan dalam tiga tahap. Tahap pertama, penulis meminta peserta mengirimkan CV dan membagikan postes kepada pengungsi terkait dengan menulis CV dan teknik wawancara sehari sebelum pelaksanaan. Tahap kedua, penulis melaksanakan kegiatan. Metode 
kegiatan berupa pelatihan dan praktik. Kegiatan pada hari pertama berupa paparan materi dan diskusi. Kegiatan pada hari kedua berupa praktik wawancara langsung dengan pihak perusahaan, PT Biopac Indonesia dan PT Yuasa. Tujuan wawancara selain untuk memberi kesempatan perusahaan menemukan kandidat yang tepat, juga melatih pengungsi untuk mempraktikkan wawancara. Setelah wawancara, dilanjutkan dengan pengisian postes.

\section{HASIL DAN PEMBAHASAN}

Kegiatan ini diselenggarakan melalui Zoom (Gambar 1). Meskipun secara daring, kegiatan ini dapat berjalan dengan lancar tanpa hambatan jaringan di pihak peserta maupun penulis. Pada hari pertama, materi yang disampaikan adalah menulis surat lamaran dan CV serta melakukan wawancara. Dalam kegiatan ini ditekankan oleh penulis bahwa menulis surat lamaran dan CV memerlukan teknik tersendiri. Dari lima belas peserta yang mengirimkan CV, tidak ada satu pun yang menyertakan surat lamaran. Hal ini menjadi titik utama penekanan pelatihan pada hari pertama. Surat lamaran merupakan pendukung CV. Keduanya harus berisi unsur persuasif kepada perusahaan. Paparan materi strategi menulis surat lamaran yang persuasif menggunakan pendekatan AIDA (attention, interest, desire, dan action), sebuah pendekatan marketing untuk diri sendiri (Bovee, C.L.\& Thill, 2018) dan menulis CV yang efektif. Selain itu, dipaparkan bagaimana mempersiapkan wawancara, menjawab pertanyaan dengan menggunakan bahasa tubuh, dan tindakan setelah wawancara.

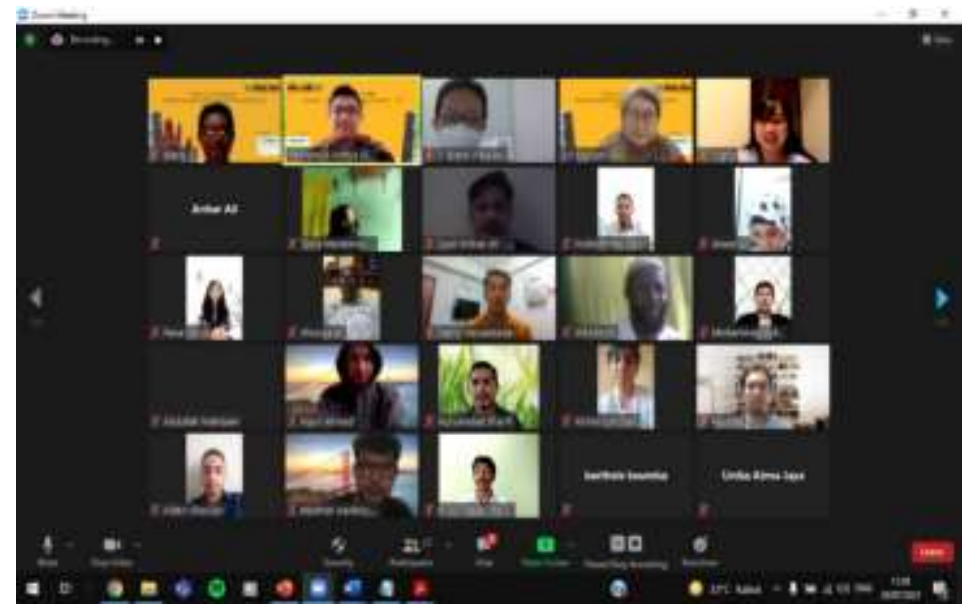

Gambar 1. Peserta dan tim dalam ruang zoom

Beberapa CV menunjukkan ketidaklengkapan, ketidaksistematisan isi, terlalu konvensional, tidak menggunakan template yang menarik, tidak menunjukkan kelebihan atau tidak menjual, dan tidak menggunakan bahasa Indonesia yang formal. Bahkan, ada peserta yang hanya mengirimkan data pribadi seperti data di dalam KTP. Hal itu disinggung penulis dalam pelatihan sebab menunjukkan ketidakseriusan peserta untuk bekerja. Seperti kebanyakan CV yang diamati, $\mathrm{CV}$ yang ditulis peserta pelatihan ini masih kurang persuasif dalam 'menjual diri' (persuasive selling) (Wijayanti \& Sulistyaningsih, 2019). Sesi pembahasan CV ini mendapat respon positif. Ada tiga peserta yang mendapat kesempatan bertanya dan sharing pengalaman mereka.

Pada hari kedua, peserta dibagi dalam tiga ruangan. Setiap ruangan, ditangani oleh pihak perusahaan yang akan memawancara. Setiap ruangan dihadari sepuluh peserta. Pada sesi ini peserta mendapat kesempatan untuk wawancara langsung dengan perwakilan perusahaan, yaitu PT Biopac Indonesia dan PT Yuwasa. Kedua perusahaan tersebut sedang membutuhkan tenaga digital marketing, design grafis, dan marketing. Dengan membaca CV yang telah dikirim ke penulis, kedua pihak perusahaan dapat mendalami langsung potensi peserta. Wawancara dilakukan dalam bahasa Indonesia atau bahasa Inggris. Bagi peserta yang tidak mengirimkan CV tetap mendapat kesempatan untuk wawancara. Pada intinya, peserta diberi kesempatan untuk 
mempraktikkan wawacara daring secara baik. Mereka harus membuka kamera dan berpakaian rapi selayaknya wawancara langsung secara luring (offline).

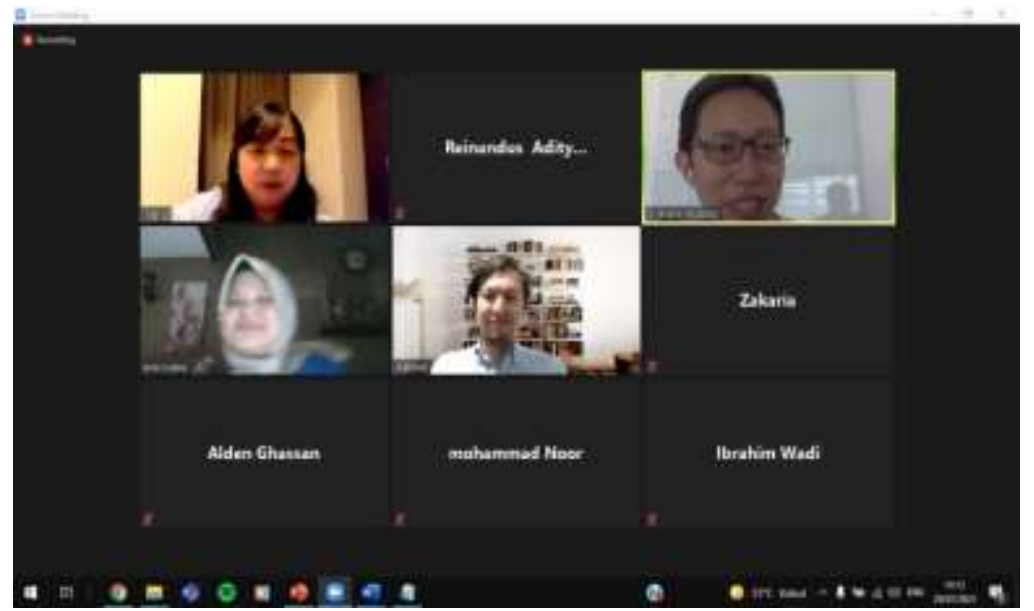

Gambar 2. Wawancara peserta dengan rekruter

Sesi wawancara mendapat respon yang tidak kalah menarik. Peserta menjawab semampunya apa yang ditanya oleh pewawancara dalam bahasa Indonesia, bahasa Inggris, atau bahasa campuran bahasa Inggris dan bahasa Indonesia. Dari wawancara ini tampak bahwa kebanyakan peserta sudah mampu berbahasa Indonesia karena sudah bertahun-tahun tinggal di Indonesia atau pernah belajar bahasa Indonesia (Wijayanti, 2020). Namun, masih ada peserta yang menggunakan penerjemah Arab-Indonesia dalam wawancara. Hal ini tentu saja membuat proses wawancara terganggu karena pewawancara dan peserta tidak berhasil membangun komunikasi yang mulus sehingga tidak tercapai tujuan. Peran penerjemah juga tidak efektif karena peserta belum dapat menunjukkan kualifikasi secara jelas. Di samping diharapkan mampu berbicara dan menjelaskan siapa diri mereka, pewawancara juga menanyakan keahlian yang dimiliki untuk mencocokkan dengan lowongan yang tersedia. Di sini peserta diminta menunjukkan portofolio dirinya.

Umumnya, wawancara berlangsung 5-10 menit per peserta. Hal ini dinyatakan peserta sangat singkat karena peserta tidak dapat menceritakan lebih banyak lagi apa yang ditanyakan. Pewawancara merasa akan mengakhiri wawancara apabila sudah tidak ada lagi informasi yang dapat digali dari peserta. Kemampuan yang tidak dibutuhkan perusahaan, seperti menjelaskan kemampuan memasak, menjahit, muncul dalam wawancara. Tentu saja pekerjaan seperti itu tidak relevan dengan posisi yang dibutuhkan perusahaan, tetapi lebih pada pekerjaan rumah tangga. Hal itu diungkap oleh perempuan pengungsi. Karena kemampuan yang dimiliki terbatas domestik, menurut Nola, pekerjaan ini tidak jarang pengungsi tawarkan kepada penduduk (Nola, 2021) dan tentu saja untuk pekerjaan domestik tersebut tidak membutuhkan wawancara formal seperti yang dipraktikkan dalam pelatihan ini.

Kendatipun momen ini merupakan momen yang tepat untuk bertemu langsung dengan pihak perusahaan yang akan merekrut peserta, tidak ada jaminan mereka dapat diterima. Hal itu sudah ditekankan penulis di awal pelatihan dan dimaklumi peserta. Kegiatan ini bertujuan bukan untuk menerima mereka bekerja, tetapi untuk membuka pengalaman mereka dalam belajar dan berlatih wawancara: bagaimana menjawab pertanyaan dalam bahasa yang jelas dan apa jenis pertanyaan yang biasanya dilontarkan rekruter.

Dari hasil evaluasi diketahui hasil tes terhadap kemampuan pemahaman mereka tentang CV dan wawancara menunjukkan nilai rata-rata peserta yang mengalami peningkatan dari 61 menjadi 75; jadi ada kenaikan 22\% (Tabel 1). Hal ini mengimplikasikan bahwa peserta sudah memahami materi lebih baik daripada sebelumnya. Dari hasil evaluasi pula diketahui bahwa 
peserta merasakan manfaat yang besar dengan adanya pelatihan dan kesempatan wawancara langsung dengan pihak perusahaan. Mereka berharap kegiatan ini ada tindak lanjutnya.

Tabel 1. Hasil prates dan postes

\begin{tabular}{lccc}
\hline & MIN & MAX & RERATA \\
\hline PRE & 20 & 100 & 61 \\
POST & 0 & 100 & 75 \\
\hline
\end{tabular}

Hasil kegiatan ini telah dipublikasikan di laman PT Seaweed Biopac Indonesia, dengan judul "PT Seaweedtama Biopac Indonesia Supports Atma Jaya Catholic University of Indonesia and UNHCR Indonesia, in Self-Improving and Vocational Education for Refugees" (https://biopac.id/news).

\section{KESIMPULAN}

Pengabdian kepada masyarakat ini telah menambah pengetahuan dan keterampilan pengungsi dalam mempersiapkan CV dan wawancara kerja. Kebutuhan itu penting karena pengungsi akan melamar kerja di perusahaan di Indonesia meskipun dengan status tidak tetap atau magang untuk mendapatkan penghasilan. Mereka merasakan manfaat dapat praktik wawacara langsung dengan dua perusahaan yang hadir pada pelatihan ini. Mereka dapat belajar dari teman yang diwawancara dan mendapat pengalaman melakukan wawancara.

Pemberdayaan bagi pengungsi perlu terus-menerus dilakukan untuk membantu pengungsi mengaktualisasikan diri dan mampu bertahan hidup di Indonesia sebagai negara transit. Dalam hal ini perlu adanya kolaborasi antara perguruan tinggi, melalui Tri Dharma Perguruan Tinggi, dan pihak perusahaan yang mau menerima pengungsi sebagai tenaga tidak tetap atau bekerja berbasis proyek. Di samping itu, bekerja sebagai tenaga yang mengandalkan keterampilan rumah tangga, seperti memasak, menjahit, dan teknisi, dapat menjadi alternatif untuk mempekerjakan pengungsi di sektor rumah tangga atau sektor informal. Pengungsi masih membutuhkan banyak keterampilan hard skill dan soft skill untuk mengembangkan diri agar dapat terserap di dunia kerja.

\section{UCAPAN TERIMA KASIH}

Penulis mengucapkan terima kasih kepada Lembaga Penelitian dan Pengabdian kepada Masyarakat Universitas Katolik Indonesia Atma Jaya yang telah memberi dukungan finansial terhadap pengabdian ini. Selain itu, juga kepada PT Biopac Indonesia dan PT Yuwasa yang telah terlibat dalam proses rekrutmen.

\section{DAFTAR PUSTAKA}

Bovee, C.L.\& Thill, J. V. (2018). Business communication today. Pearson.

Elvianti, W. (2020). Pemberdayaan Pemuda dalam Pengenalan Budaya dan Bahasa Indonesia untuk Pengungsi Anak-Anak di Cisarua, Bogor. E-Dimas: Jurnal Pengabdian Kepada Masyarakat, 11(4), 460-467. https://doi.org/10.26877/e-dimas.v11i4.4122

Jamaan, A., Saeri, M., Olivia, Y., Nizmi, Y. E., \& Iskandar, I. (2020). Kewirausahaan bagi pengungsi asing dan pencari suaka di Pekanbaru pada masa pandemi Covid-19. Unri Conference Series: Community Engagement, 2, 275-280. https://doi.org/10.31258/unricsce.2.275-280

Nola, L. (2021). Refugee Employment Prohibition in Indonesia. ICILS. https://doi.org/10.4108/eai.1-7-2020.2303641 
Oktavia, Y., \& Putra, E. E. (2018). Penerapan Keterampilan Berbahasa Indonesia Berbasis Pendekatan Experience Based Education Pegawai Dishub Battam. DINAMISIA-Jurnal Pengabdian Kepada Masyarakat, 2(2), 261-269.

Wijayanti, S. H. (2020). Kecakapan Pengungsi dalam Berbahasa Indonesia. Indonesian Language Education and Literature, 5(2), 171. https://doi.org/10.24235/ileal.v5i2.5983

Wijayanti, S. H., \& Sulistyaningsih, E. (2019). Format, Design and Content of Curriculum Vitae in a Developing Country. Proceedings of the Social and Humaniora Research Symposium, 328-332.

Yani, Y. M., \& Zulkarnain, Z. (2019). Dimensi Penanganan dalam Kasus Pengungsi Internasional; Teori dan Praktik. Jurnal Sosial dan Humaniora, 4(7), 1-14. https://doi.org/10.47313/ppl.v4i7.592

www.unhcr.org/id 